\title{
ROTEIRO PEDAGÓGICO: UM INSTRUMENTO PARA A APRENDIZAGEM DE CONCEITOS DE FÍSICA
}

\section{Pedagogical Schedule: a tool for learning physics concepts}

\author{
Neiva Irma Jost Manzini ${ }^{1}$
}

\begin{abstract}
Resumo: O objetivo desta investigação foi analisar as possibilidades e os limites de uma experiência de ensino-aprendizagem de conteúdos de física, realizada com alunos do curso de Licenciatura em Física e fundamentada na "epistemologia genética" de Jean Piaget. Como metodologia de ensino foi construído o roteiro pedagógico, que tem como objetivo identificar e promover a construção e reconstrução de processos cognitivos sob a perspectiva piagetiana, visando possibilitar a compreensão das grandezas físicas envolvidas nos fenômenos e das relações lógico-matemáticas entre elas. Contatou-se que essa atividade pedagógica auxilia os alunos na construção do conhecimento e na formação da equação matemática que expressa o fenômeno físico estudado.
\end{abstract}

Palavras-chave: Aprendizagem. Epistemologia. Física

\begin{abstract}
This investigation aims to analyze the possibilities and limits of a teaching-and-learning experience about physics subjects, carried out with students from a Physics Degree and its basis is in the "Genetics Epistemology", of Jean Piaget. As a methodology of teaching, it uses a pedagogical schedule, that aims to identify and promote the construction and reconstruction of cognitive processes using Piaget's perspective, aiming to make possible the comprehension of the magnitudes in Physics involved in the phenomenon and logical-mathematical relations between them. I noticed that this pedagogical activity helps students in the acquisition of their knowledge and the formation of mathematical equations that expresses the physical phenomenon studied.
\end{abstract}

Key words: Learning. Epistemology. Physics.

\footnotetext{
${ }^{1}$ Doutora em Educação; docente, Centro de Ciências Exatas e Tecnológicas, Universidade do Vale do Rio dos Sinos (Unisinos). São Leopoldo, RS. <neivam@unisinos.br>
}

Rua Três Passos, 113

Centro - Novo Hamburgo, RS

93.520-580 
Começo as reflexões sobre este tema expressando minha preocupação, como professora de física na universidade, com o processo de ensino-aprendizagem de conteúdos dessa área de conhecimento. Pude observar, durante minha caminhada, que, em todos os níveis de ensino, a maioria dos alunos não conseguia transferir os conteúdos de física para situações de seu cotidiano e tinha dificuldades em aprender conteúdos de matemática. Na universidade, tenho observado que eles não dominam certos conteúdos físicos do nível médio, o que gera dificuldades na compreensão dos conteúdos da educação superior. Com a carga horária destinada às disciplinas na graduação os alunos não conseguem sanar suas deficiências, determinadas lacunas vão permanecendo e outras surgindo. Esse quadro preocupa-me muito e foi um dos motivos por que escolhi trabalhar, no mestrado, com modelos de física para a aprendizagem de conteúdos matemáticos. Nessa pesquisa, pude observar que os alunos manifestavam mais interesse em aprender os conteúdos matemáticos quando aplicados a uma situação real.

Penso que a não-vinculação dos conteúdos a um contexto, situação que também acompanha o ensino da física, dificulta que transpareça sua função: auxiliar o homem a entender o funcionamento físico das coisas de seu mundo.

Em visitas que faço às escolas de Ensino Médio, tenho observado que, quando os estagiários iniciam suas aulas relacionando a história da física ao conteúdo ministrado, seus alunos mostram-se interessados e motivados.

A história da física revela um processo evolutivo de construção e reconstrução de conceitos científicos para explicar os fenômenos. À medida que esses conteúdos explicam os fatos observados pelo homem, passam a ter significado e despertar o interesse das pessoas, sendo transmitidos às novas gerações, principalmente pelas escolas e universidades. Existe, pois, necessidade de compreender esses conteúdos, a fim de conhecer o que já foi elaborado e continuar a criar mecanismos que atendam às necessidades do homem no percurso da evolução histórica das ciências. Assim, o ambiente escolar ou acadêmico precisa estar em constante movimento de implementação de metodologias e recursos que desenvolvam conteúdos e preparem o cidadão para refletir sobre as coisas de seu mundo.

A história da física serve não apenas para situar determinado conteúdo em determinado tempo, mas, também, para ajudar o aluno a compreender processos lógicos que possibilitaram o surgimento de novos conhecimentos dentro de um contexto histórico concreto. Penso que o professor poderá conseguir que seus alunos tenham uma aprendizagem mais significativa de conteúdos físicos se ele próprio conhecer esse processo e procurar entender os mecanismos lógicos que possibilitaram a evolução da física em sua relação com o quadro de significações de uma época histórica. No processo de construção do conhecimento, observo que, diversas vezes, os alunos passavam por etapas vivenciadas pelos cientistas e procuravam construir e reconstruir conceitos e procedimentos por meio do raciocínio e da observação, vinculando-os também à realidade.

A partir dessas reflexões, configurou-se a idéia de realizar-se uma pesquisa, para investigar uma experiência de ensino-aprendizagem em que os alunos, trabalhando em grupo cooperativamente, construíssem modelos físicos, chegando a uma aprendizagem efetiva. Com esse fim, baseando-me na teoria "epistemologia genética" de Jean Piaget, desenvolvi uma metodologia a que denominei roteiro pedagógico. Esse recurso didático teve como objetivo organizar as atividades de ensino-aprendizagem dos alunos, permitindo a observação dos processos cognitivos e as reflexões necessárias para a compreensão das grandezas físicas envolvidas 
Roteiro pedagógico: um instrumento...

nos fenômenos e das relações lógico-matemáticas entre elas. Ao mesmo tempo, as diferentes etapas do roteiro pedagógico foram associadas a períodos da evolução da história da física.

Essa metodologia foi elaborada durante uma experiência de ensino-aprendizagem de conteúdos de física, realizada durante quatro semestres, com alunos do curso de Licenciatura em Física da Universidade do Vale do Rio dos Sinos (Unisinos). A investigação dessa experiência constituiu minha tese de doutorado.

Neste artigo, trago reflexões, enfocando principalmente o roteiro pedagógico, buscando compreender os processos cognitivos envolvidos nas diferentes etapas de sua aplicação, à luz da teoria piagetiana. Com isso, inicialmente apresento idéias dessa teoria que embasaram o trabalho; a seguir, descrevo e analiso as diferentes etapas do roteiro pedagógico; e, finalizando, teço reflexões sobre o processo e o produto desta experiência.

\section{Os fundamentos teóricos da investigação}

Apresento, neste item, as idéias embasadoras do trabalho que foi realizado, as quais têm como fundamento a teoria da "epistemologia genética" de Jean Piaget.

A preocupação fundamental da epistemologia genética é compreender como se adquire o conhecimento. Com esse objetivo, Piaget investigou, em sua teoria cognitivista, os mecanismos que aparecem na construção do conhecimento, buscando explicitar como começam a surgir a partir da interação entre sujeito e objeto. Segundo o autor, a construção do conhecimento inicia-se a partir da interação do sujeito com o objeto e, nesse processo, determinadas estruturas cognitivas são construídas e reconstruídas, à medida que o conhecimento vai sendo elaborado.

Piaget (1983) considera as idéias de equilibração, descentração e reversibilidade de suma importância para a compreensão de sua teoria. Aponta, entretanto, a teoria da abstração reflexiva como a mais importante explicação para o desenvolvimento do intelecto, conceito que, na teoria do conhecimento de Piaget, tem um papel central. Em sentido literal, "reflexione" (refletir) significa voltar para si mesmo, pensar sobre si mesmo. Reflexão, no sentido filosófico da palavra, significa atentar-se para o próprio fazer, para pensamentos, representações e sentimentos. Abstrair pode ser entendido como isolar uma qualidade perceptível de um objeto. Quando se abstrai a cor de uma folha, retém-se seu verde individual. Para chegar ao conceito de verde, é necessário um segundo passo: a generalização. O conceito de verde representa toda uma classe de tonalidades de cor, abstração composta pelos processos de isolar e generalizar que denomina-se abstração empírica.

Piaget estabelece a distinção entre abstração empírica e abstração reflexionante. Contrariamente à abstração empírica, em que os dados são obtidos dos caracteres pertencentes à natureza do objeto, a leitura dessas "experiências lógico-matemáticas", ou seja, a abstração reflexionante, recai apenas sobre as propriedades introduzidas pela ação do sujeito no objeto (ações de reunir, ordenar etc.). Uma vez que as ações são interiorizadas em operações, elas podem ser executadas simbolicamente e, portanto, dedutivamente.

A maior parte dos conceitos lógico-matemáticos é derivada das abstrações reflexionantes. A abstração empírica leva à constatação. A abstração reflexionante atinge maior profundidade e leva à compreensão. Na abstração reflexionante, a construção e a reflexão atuam 
juntas, e, por meio desse processo, determinadas estruturas de comportamento e conhecimento são projetadas a um nível superior, tornando-se conscientes. A esse processo Piaget denominou "tomada de consciência".

\section{Psicogênese e a ontogênese}

A psicogênese piagetiana estabelece que estágios sucessivos da aquisição de conhecimentos pelos sujeitos são seqüenciais e passam por reorganização de um nível a outro. Isso significa que os estágios inferiores são integrados nos estágios superiores, sendo que sua natureza só é explicada pela análise dos estágios que os precederam. Piaget e Garcia (1987) concluíram que a ciência também passa de um nível a outro, fazendo, ao longo do processo histórico de sua evolução, uma reavaliação e integração de conhecimentos. Segundo esses autores, as etapas de transformação do conhecimento científico são fundamentalmente as mesmas encontradas no desenvolvimento do pensamento infantil. Essa identificação é, ao mesmo tempo, de cunho genético e histórico-crítico.

A história da ciência constitui um laboratório epistemológico, e a solução de um problema científico faz surgir novas questões (de natureza científica ou epistemológica), como é o caso da teoria newtoniana da gravitação. Aí, faz-se necessário saber como interpretar a evolução de uma ciência e compreender como ela passa de uma etapa para a seguinte, ou seja: quais os mecanismos cognitivos em jogo em cada etapa e quais aqueles que possibilitam atingir o nível superior. Como o sujeito que constrói seu conhecimento passando por várias etapas e adquirindo novos conhecimentos, à medida que interage com o meio em um processo ilimitado a ciência também se encontra em um perpétuo devir.

Para Piaget e Garcia (1987), ao desenvolvimento das operações do sujeito, caracterizado pelos períodos sucessivos - o pré-operatório, o período das operações concretas e o período das operações hipotético-dedutivas -, correspondem, respectivamente, as etapas intra, inter e trans dos conhecimentos adquiridos. Os autores justificam o número de três períodos, fazendo um paralelo com a "tese", "antítese" e "síntese" da dialética clássica.

Segundo Piaget e Garcia (1987, p. 162):

No que toca às finalidades sucessivas e últimas do processo que conduz do intra e inter ao trans, a resposta parece suficientemente evidente: tanto o matemático como a criança de um certo nível não se contentam nunca em verificar ou descobrir (o que consiste em inventar): a cada etapa eles querem atingir as razões daquilo que encontram.

$\mathrm{Na}$ etapa "intra", aparece somente a negação das classes, existindo dificuldades na regulação das negações. As reciprocidades, as quais constituem transformações gerais, são facilmente encontradas nos agrupamentos de relações, característicos da etapa "interoperacional".

Na etapa "transoperacional” há as transformações e a síntese entre elas, chegando-se à construção de "estruturas". A mais notável das estruturas é aquela que relaciona as partes e o todo, sem se limitar às classes e relações disjuntas ou encaixáveis, unindo, num todo, inversões (negações) e reciprocidades. Evidencia, assim, a estrutura de grupo designada de INRC, 
Roteiro pedagógico: um instrumento...

em que uma operação pode permanecer inalterada $\mathrm{I}$, invertida $\mathrm{N}$, transformada na sua recíproca R ou na sua correlata C. Esse grupo só é observado nos sujeitos a partir de 11 e 12 anos, início do período em que eles se tornam capazes de construir tais sínteses por composições em ações e interferências progressivas, quando se trata de coordenar inversões e reciprocidades num mesmo sistema total.

Segundo Piaget e Garcia (1987), a tríade intra, inter e trans é uma sucessão dialética e utiliza os seguintes símbolos: Ia (intra), Ir (inter) e T(trans). A tríade IaIrT obedece necessariamente a essa ordem, uma vez que a elaboração de $\mathrm{T}$, numa totalidade com as propriedades, supõe a formação de algumas dessas transformações em Ir e que estas implicam o conhecimento das características analisadas em Ia. Essas elaborações comportam, em todos os níveis, processos psicogenéticos ou históricos comuns e cada uma das grandes etapas históricas comporta subetapas (por exemplo, no nível T temos as fases trans-intra, trans-inter e trans-trans).

Para Piaget e Garcia (1987, p. 173):

Essas hierarquias cognitivas comportam duas espécies de encaixes. Uns são próativos, por alongamento dos domínios no decorrer dos períodos sucessivos da construção dos conhecimentos. Mas outros são retroativos, porque o adquirido a um nível $n$ pode enriquecer posteriormente as relações já estabelecidas em níveis anteriores $\mathrm{n}-1$, por exemplo, em química em que as explicações eletrônicas chegaram a uma concepção nova das valências.

\section{Metodologia da pesquisa}

Inicialmente, foi feito um convite verbal a algumas turmas do curso de Licenciatura em Física da Unisinos para que os alunos participassem do projeto como voluntários, selecionando-se os que se apresentaram interessados em colaborar com a pesquisa. Durante o primeiro ano, seis alunos participaram; no segundo ano, dois desistiram e outros quatro ingressaram, por meio de convites feitos pelos próprios estudantes que continuaram no grupo.

Os alunos reuniam-se semanalmente, durante duas horas, para participar da experiência em que foi desenvolvida a metodologia, denominada roteiro pedagógico, explicada detalhadamente na seção seguinte.

No primeiro ano, foi trabalhado o material concreto, aplicando a teoria da epistemologia genética de Piaget. O roteiro pedagógico foi construído a partir de observações, entrevistas dos alunos realizadas pela orientadora da pesquisa e de materiais escritos pelos componentes do grupo ao final do primeiro ano. No segundo ano, aconteceram a interação dos alunos com o material concreto e a aplicação do roteiro pedagógico, o qual foi sendo aperfeiçoado nesse período.

Os encontros foram filmados e transcritos em fichas de observação e, a partir das constatações feitas em sala de aula e dos depoimentos dos alunos, a eficácia da metodologia foi demonstrada. A fim de validar a metodologia levou-se em consideração o parecer oral e escrito dos alunos (auto-avaliação). Tanto durante a interação do grupo quanto na confecção do roteiro houve cuidado para que os alunos pudessem sentir-se livres para interagir entre si e com a metodologia. Uma técnica que utilizei era sair da sala de aula e os deixar à vontade, para que minha opinião ou presença não os influenciasse de alguma maneira. Observei que a moti- 
Manzini, N. I. J.

vação dos alunos para compreender determinados fenômenos físicos era intensa, de modo que, muitas vezes, havia reflexões manifestadas por meio de longos diálogos entre os integrantes. Isso fazia com que as conversações e abstrações ultrapassassem o horário-limite determinado para a atividade.

\section{O roteiro pedagógico: uma metodologia de aprendizagem efetiva}

A metodologia utilizada no processo de ensino-aprendizagem de conteúdos da física, à que denominei roteiro pedagógico, teve como objetivos organizar em diferentes etapas atividades de aprendizagem dos alunos, promovendo as reflexões necessárias para a compreensão efetiva de conteúdos de física, e, ao mesmo tempo, possibilitar a observação e análise dos processos cognitivos envolvidos.

O roteiro pedagógico é dividido em quatro partes, cada uma acompanhada de instruções com o propósito de ajudar os alunos na observação e compreensão progressiva do fenômeno físico estudado. Acredito que as duas primeiras partes do roteiro pedagógico estejam mais relacionadas à aproximação da objetividade; as duas últimas, à formação do conceito, à generalidade e permanência fora do tempo, ou seja: ao pensamento.

\section{Análise da experiência e do roteiro pedagógico}

As instruções iniciais para a realização dos experimentos - referentes ao modo como os alunos deveriam manipular o material concreto e ao que deveria ser observado - foram dadas verbalmente. Em seguida, foram explicadas as questões escritas na primeira parte do roteiro pedagógico e os alunos, questionados sobre alguns conceitos básicos e fundamentais para a compreensão do fenômeno físico a ser observado. A experiência mostrou que é necessário um cuidado especial com as orientações iniciais e a condução durante todo o experimento, porque o resultado esperado está diretamente relacionado a esses procedimentos.

A seguir, os procedimentos e a análise das diferentes partes do roteiro pedagógico.

\section{Primeira parte do roteiro pedagógico - Interação com o material concreto}

As questões escritas na primeira parte do roteiro pedagógico tiveram por objetivo conduzir os procedimentos dos alunos, para que ocorressem construções e reflexões no processo de observação do fenômeno físico, por meio da manipulação do material concreto. Segundo Piaget: "Qualquer objeto é o ponto de interseção de todas as suas ligações possíveis com o mundo exterior, e o mesmo objeto pode dar lugar a numerosos tipos de interação, as quais poderão fornecer outros conceitos" (1981, p. 38). Nessa parte do roteiro pedagógico, aplicado à experiência denominada "Experiência da indução eletromagnética com um imã e uma bobina", apresentamos instruções, tais como:

- passe lentamente até 3/4 do ímã (iniciando pelo pólo norte) pelo centro do solenóide. Observe o galvanômetro.

- passe rapidamente até $3 / 4$ do ímã (iniciando pelo pólo norte) pelo centro do solenóide. Observe o galvanômetro. 
Roteiro pedagógico: um instrumento...

Quando os alunos responderam à primeira parte do roteiro pedagógico desse experimento, passaram a examinar o equipamento, observando o sentido da corrente elétrica, mostrado pelo movimento da agulha no galvanômetro em função do movimento do ímã. Os alunos P, J e A estabeleceram o seguinte diálogo:

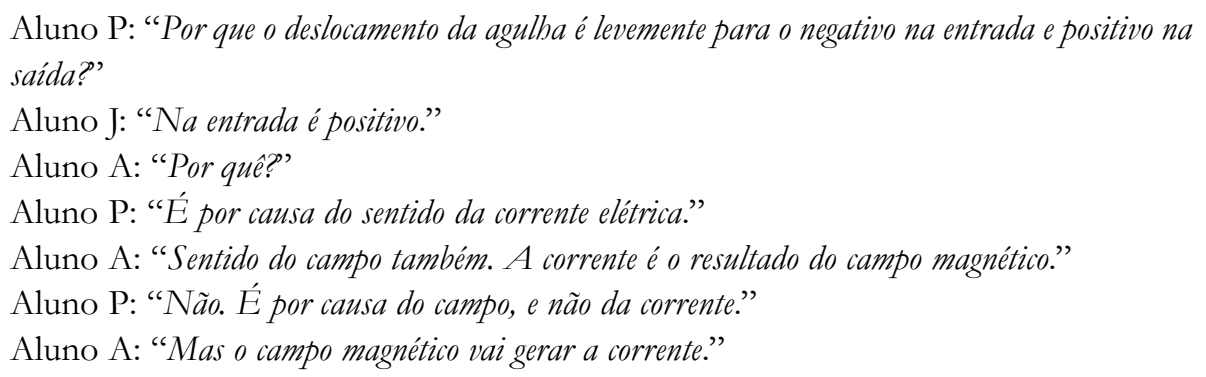

No decorrer do experimento, observei que os alunos interagiam muito entre si e com o material concreto e que eles mesmos propunham diferentes formas de interação. Nesse momento, o nível de construção corresponde à fase intra-operacional.

Os alunos procuravam analisar diversas propriedades internas do objeto de estudo ou as conseqüências imediatas de sua ação, sendo a análise interna da operação em jogo acompanhada de erros, corrigidos sucessivamente. A ação repetível, ou seja, a operação correta, caracteriza essa etapa, mas ainda sem o poder de visualizá-la num sistema de condições ou conseqüências que a inseririam numa totalidade de transformações solidárias. Os alunos mostravam-se interessados em descobrir o fato observado e estimulados em manipular o material concreto. A satisfação dessa interação pode ser observada pela fala do aluno D, que afirma: "Mostrar o equipamento é uma coisa, o aluno trabalhar é outra. Mexer, tocar, sentir. Ver o professor fazendo é uma coisa, mas quando a gente pega e move, a gente consegue visualizar".

\section{Segunda parte do roteiro pedagógico - Tabelas-verdade e o grupo INRC}

Optei por utilizar as tabelas-verdade com objetivo de promover a reflexão, reforçar as estruturas cognitivas já existentes e ajudar os alunos a confirmarem suas hipóteses e a fazerem observações, privilegiando o grupo INRC. As tabelas-verdade consistem no conjunto de proposições logicamente conectadas que afirmam ou negam uma relação entre grandezas físicas presentes em um fenômeno físico e em uma conclusão, que poderá ser verdadeira ou falsa, conforme a relação entre as proposições antecedentes.

As tabelas-verdade são acompanhadas de um texto com perguntas e afirmações, que têm objetivo de instigar o aluno a trabalhar com operações lógicas e com o grupo INRC. Para ilustrar o procedimento utilizado, apresentamos, a seguir, uma tabela-verdade elaborada para um roteiro pedagógico, a qual vem acompanhada de um texto. Esse roteiro foi utilizado para a experiência denominada "Experiência da indução eletromagnética com um ímã e uma bobina".

Texto apresentado: "O campo magnético no interior da bobina não varia com o tempo e a velocidade do imã varia com o tempo. Comente a afirmação. Formule hipóteses, a partir das seguintes proposições:

$v(t)$ a velocidade do imã varia com tempo.

$B(t)$ o campo magnético no interior da bobina varia com o tempo. 
A primeira coluna afirma a proposição v(t) como verdadeira $(V)$ ou nega-a como falsa $(F)$. A segunda coluna afirma a proposição $B(t)$ como verdadeira $(V)$ ou nega-a $(F)$.

A partir da observação e interação com o material concreto, os alunos refletiam sobre as proposições e completavam a terceira coluna da tabela $(\mathrm{R}) \operatorname{com} \mathrm{V}$ (verdadeiro) ou $\mathrm{F}$ (falso). Nessa coluna $(\mathrm{R})$, aparece o resultado da relação das proposições $\mathrm{v}(\mathrm{t})$ e $\mathrm{B}(\mathrm{t})$. Por exemplo: na primeira linha da tabela, as duas proposições são verdadeiras, ou seja, a velocidade do ímã varia com o tempo (V) e o campo magnético no interior da bobina varia com o tempo (V). Então o resultado $(\mathrm{R})$ dessa relação também é verdadeiro $(\mathrm{V})$. Na segunda linha, a primeira proposição, a velocidade do ímã varia com tempo, é verdadeira $(\mathrm{V})$ e a segunda proposição falsa $(\mathrm{F})$ : o campo magnético no interior da bobina não varia com o tempo. O resultado $(\mathrm{R})$ dessa relação (a velocidade do ímã varia com tempo e o campo magnético no interior da bobina não varia com o tempo) é, portanto, falso (F).

Tabela 1. Tabelas-verdade.

\begin{tabular}{ccc}
\hline$v(t)$ & $B(t)$ & $R$ \\
\hline$V$ & $V$ & $V$ \\
$V$ & $F$ & $F$ \\
$F$ & $V$ & $F$ \\
$F$ & $F$ & $V$ \\
\hline
\end{tabular}

Com a utilização das tabelas-verdade, os alunos manifestaram ter tido maior clareza na compreensão do fenômeno físico e conseguido estabelecer as relações lógico-matemáticas. Eles afirmaram que as tabelas-verdade funcionam como uma avaliação do conhecimento. Sugeriram o aumento do número de tabelas-verdade, para que fosse possível visualizar melhor o fenômeno e obter maior compreensão das grandezas físicas envolvidas e de suas relações lógicas.

Em cada etapa existe uma reorganização dos conhecimentos adquiridos durante a etapa precedente e se repete uma sucessão das subetapas intra, inter e trans. A generalização construtiva não consiste em assimilar os conteúdos novos às formas já existentes, mas em gerar novas formas e novos conteúdos, ou seja, novas organizações estruturais.

Em um dos momentos, no qual os alunos completaram as tabelas-verdade do roteiro pedagógico, revelou-se a fase inter-trans de construção do conhecimento físico: foi quando eles concluíram que a passagem da corrente elétrica num fio condutor gera um campo magnético ao redor do mesmo. Nessa fase, os estudantes manifestaram compreender o fenômeno estudado, relacionando-o a outras situações vivenciadas. Apresentaram, no entanto, certa incerteza ao descreverem os fatos observados. 
Roteiro pedagógico: um instrumento...

As falas a seguir caracterizam esse momento.

O aluno P disse: "Eu acho que é como o fio da nossa casa, sai do pólo positivo para o negativo".

$\mathrm{O}$ aluno D afirmou: "Acho que o sentido tanto faz".

O aluno P concluiu: "Como aquele cara que descobriu o eletroímã, com a bússola. Tem pólo

Norte e pólo Sul, assim como o campo magnético da Terra. É claro que existe o campo magnético no fio condutor".

Durante a realização da segunda etapa, os alunos refletiram sobre suas ações e observações e procuraram encontrar respostas para suas hipóteses. Perguntei a eles se as tabelas ajudavam ou não e um respondeu: "Analisando as tabelas juntas se consegue obter mais informações para construir e analisar os gráficos. Ajudam para confirmar as hipóteses. Durante o processo, vão surgindo dúvidas e as tabelas respondem essas dúvidas e fica mais fácil'.

\section{Terceira parte do roteiro pedagógico - Prova clínica}

A prova clínica consiste de uma prova oral e tem por objetivo promover as reflexões necessárias, conduzindo à tomada de consciência do fenômeno físico observado e ao estabelecimento das possíveis relações lógico-matemáticas entre as grandezas físicas envolvidas, o que auxilia os alunos a estabelecer a equação matemática. Durante essa prova, o professor interage com os alunos, esclarecendo os conteúdos em que têm dificuldades. A afirmação de um aluno ilustra esse processo: "Eu só pensei que o campo magnético poderia ser uma grandeza vetorial depois que reli a questão. Depois da prova clínica foi que entendi".

A pergunta a seguir, formulada nesse processo, pode esclarecer um pouco mais sobre esse momento de construção do conhecimento: "Já tinha passado por suas cabeças que o campo magnético poderia ser uma grandeza vetorial?".

O aluno D respondeu: "Não. Eu só pensei que o campo magnético poderia ser uma grandeza vetorial depois que li a questão. Depois da prova clínica foi que entendi."

O aluno P completou: "Eu também não tinha parado para pensar se o campo magnético é ou não uma grandeza vetorial, só depois da prova clínica."

O aluno J afirmou: "Eu já sabia, mas, a partir da pergunta da Neiva, en passei a utilizar o conceito de vetor campo magnético, no experimento."

A manifestação do aluno D na realização da prova clínica parece indicar que, durante a experiência, certas estruturas cognitivas foram construídas ou reconstruídas: "Estou bem mais preparado. Se a gente consegue entender qualquer pergunta que o aluno fizer, a gente consegue fazer experimentalmente o experimento para poder responder".

\section{Quarta parte do roteiro pedagógico - Tarefa escrita individual}

A quarta e última parte do roteiro pedagógico tem como objetivo avaliar se houve aprendizagem efetiva, mediante questões que envolvem aplicações dos conteúdos desenvolvidos em situações similares do cotidiano do aluno. Segundo a teoria piagetiana, a aprendizagem efetiva ocorre quando o aluno se encontra na fase "trans", o que significa que ele compreen- 
deu o fenômeno físico estudado e tem condições de aplicar os conceitos apreendidos em situações que envolvem fenômenos similares. Nessa etapa, surgem as estruturas que relacionam as partes e o todo, características da reversibilidade que une as inversões (negações) e as reciprocidades.

Para ilustrar a quarta parte do roteiro, cito uma pergunta feita nessa etapa do experimento "Experiência da força magnética sobre uma corrente elétrica": "Hipoteticamente, o que aconteceria se o campo magnético do fio condutor aumentasse quando a corrente elétrica que circula no mesmo diminuísse?"

A pergunta contraria o fato observado pelos alunos e foi feita com objetivo de verificar, por meio das respostas, se suas construções contemplam as operações lógico-matemáticas do grupo INRC. O aluno D respondeu: "Não consigo imaginar uma situação como essa, pois o campo magnético está relacionado com o campo elétrico, e, na minha opinião, para acontecer o inverso, de o campo magnético aumentar e a corrente diminuir, talvez somente com o emprego de outros materiais".

$\mathrm{O}$ aluno $\mathrm{D}$, pela reversibilidade do pensamento, concluiu que o inverso do fato observado não poderia acontecer. De modo correto e consciente, esse aluno afirmou que a relação lógico-matemática estabelecida na hipótese não é verdadeira. E hipoteticamente sugeriu, por uma necessidade lógica, uma outra relação.

Nessa etapa, os alunos testaram seus conhecimentos e suas hipóteses, analisando outras situações. A seguir, a ilustração dessa etapa da prova com algumas questões formuladas na realização do experimento "Experiência da indução eletromagnética com um ímã e uma bobina":

- Cite algum(ns) aparelho(s) que, no seu(s) funcionamento(s), se evidenciam as leis de Faraday e Lenz.

- Cite as grandezas físicas envolvidas e conceitue-as. Explique detalhadamente onde elas se manifestam nos aparelhos citados, identificando causas e efeitos.

Os alunos responderam satisfatoriamente a essas questões e revelaram, com suas respostas, momentos de reflexão. Um exemplo de construção de conhecimento característico da fase trans, observado na fala do aluno A.

Durante a última etapa do roteiro pedagógico do experimento, o aluno A disse: "Tem aquele experimento no qual gira uma bobina dentro de um imã e dai gera uma voltagem". Esse aluno apontou para uma situação semelhante, que envolve o mesmo princípio físico, o que indica que chegou à tomada de consciência do fenômeno físico estudado, conseguindo identificar e aplicar o conteúdo em outra situação. O interessante, nesse caso, é que ele reviveu seu contato com o material concreto com o qual interagiu antes e relacionou a situação já vivenciada ao conteúdo agora aprendido.

\section{Considerações finais}

Os textos contidos no roteiro pedagógico tiveram como objetivo propiciar ao aluno que ele fosse gradativamente construindo seus conhecimentos sobre determinado fenômeno físico. Não deveriam, entretanto, conduzi-lo diretamente aos conceitos físicos envolvidos.

Com essa metodologia, observei que os alunos trabalharam motivados e ficaram bastante satisfeitos quando atingiram o equilíbrio no processo do conhecimento. Penso que o professor que constrói o conhecimento com seus alunos precisa conhecer profundamente o conteúdo a ser desenvolvido e, também, os processos cognitivos envolvidos em sua aprendi- 
Roteiro pedagógico: um instrumento...

zagem. Muitas vezes, essa necessidade é desconhecida por aquele professor que simplesmente "transmite" os conhecimentos.

Identificar o uso das operações formais exige mais do que propor tabelas-verdade. Ainda que o professor não trabalhe todo o grupo INRC, trabalhar a reversibilidade é fundamental para atingir os objetivos do roteiro pedagógico. É necessário reconhecer o grupo INRC nas atitudes e na fala dos alunos, pois fazer essa leitura no raciocínio do aluno é fundamental para o processo ensino-aprendizagem. Penso que o professor poderá, com mais eficiência, ajudar seu aluno a compreender determinado conteúdo se souber em que nível de construção do conhecimento desse conteúdo o aluno se encontra e o que ele está precisando compreender, observar, relacionar etc... para reconstruir estruturas cognitivas na aquisição do novo conhecimento.

Observei que, no início do processo ensino-aprendizagem de física, os alunos encontravam-se na fase "intra". Conforme foram avançando nesse processo de construção atingiram a fase "inter" e, somente na última etapa do experimento, quando responderam à última parte do roteiro pedagógico, chegaram à fase "trans" do conhecimento físico então construído.

Dependendo do fenômeno físico abordado, o professor sentirá a necessidade de ampliar o roteiro pedagógico, com maior número de questões, tabelas-verdade e aplicações, ou seja: reconstruindo-o, a fim de possibilitar ao aluno a aprendizagem dos conteúdos estudados. O roteiro pedagógico pode ser considerado flexível e aberto, porque é passível de ser ampliado ou modificado, o professor decidindo o momento mais adequado para interferir no processo de construção do aluno.

Conhecendo os processos lógico-matemáticos e físicos que foram utilizados ao longo da história da física, bem como as experiências construídas e seus aperfeiçoamentos, o professor de física poderá enriquecer o roteiro pedagógico. Identificar, nos diferentes níveis de construção dos conceitos físicos, as auto-regulações de seus alunos, possibilitando, assim, que eles façam um maior número de observações, reflexões e hipóteses, fatores necessários para a compreensão de um fenômeno físico.

O trabalho desenvolvido constitui um primeiro passo para uma ação pedagógica fundamentada na teoria piagetiana, voltada para a compreensão de conteúdos físicos. Muitas vezes existe a necessidade de aperfeiçoar o roteiro pedagógico - incluindo outras experiências -, com novos roteiros, que forneçam subsídios para a compreensão dos conteúdos estudados. Outro caminho que pode ser seguido para melhorar a utilização desse instrumento relaciona-se à segunda parte do roteiro pedagógico. As tabelas-verdade comportam duas proposições, tendo esse número sido suficiente para os conteúdos abordados. No entanto, essa parte poderá ser melhorada, incluindo-se tabelas-verdade que envolvam três ou mais proposições, e, conseqüentemente, aumentando o número de relações lógico-matemáticas que podem ser estabelecidas. Além disso, é possível aumentar o número de questões que envolvem o grupo INRC, sempre que o experimento realizado não for suficiente para a compreensão de determinado fenômeno físico. Para possibilitar que o aluno chegue à tomada de consciência poderão ser incluídos, também, outros experimentos e novos roteiros pedagógicos, permitindo a identificação de um número maior de estruturas cognitivas e relações lógico-matemáticas, a fim de ampliar a combinatória e o grupo INRC na construção desse instrumento, favorecendo maior compreensão das construções elaboradas pelos alunos.

A utilização do roteiro pedagógico pode promover uma ação pedagógica voltada à neces- 
Manzini, N. I. J.

sidade que o aluno tem de obter explicações para as coisas de seu mundo e oferecer aos professores dos ensinos Fundamental e Médio um instrumento que permita acompanhar, de forma mais próxima, o pensamento de seus alunos, fornecendo subsídios para uma prática pedagógica comprometida com suas necessidades.

\section{Referências}

PIAGET, J. Os pensadores. São Paulo: Vitor Civita, 1983.

Lógica e conhecimento científico. Porto: Civilização, 1981. 2 v.

PIAJET, J.; GARCIA, R. Psicogênese e história das ciências. Lisboa: Dom Quixote, 1987.

Artigo recebido em julho de 2006 e aceito em março de 2007. 